\title{
Looking like Limulus? - Retinula axons and visual neuropils of the median and lateral eyes of scorpions
}

Tobias Lehmann ${ }^{1,2^{*}}$ and Roland R Melzer ${ }^{1,2,3}$

\begin{abstract}
Background: Despite ongoing interest in the neurophysiology of visual systems in scorpions, aspects of their neuroanatomy have received little attention. Lately sets of neuroanatomical characters have contributed important arguments to the discussion of arthropod ground patterns and phylogeny. In various attempts to reconstruct phylogeny (from morphological, morphological + molecular, or molecular data) scorpions were placed either as basalmost Arachnida, or within Arachnida with changing sister-group relationships, or grouped with the extinct Eurypterida and Xiphosura inside the Merostomata. Thus, the position of scorpions is a key to understanding chelicerate evolution. To shed more light on this, the present study for the first time combines various techniques (Cobalt fills, Dil / DiO labelling, osmium-ethyl gallate procedure, and AMIRA 3D-reconstruction) to explore central projections and visual neuropils of median and lateral eyes in Euscorpius italicus (Herbst, 1800) and E. hadzii Di Caporiacco, 1950.

Results: Scorpion median eye retinula cells are linked to a first and a second visual neuropil, while some fibres additionally connect the median eyes with the arcuate body. The lateral eye retinula cells are linked to a first and a second visual neuropil as well, with the second neuropil being partly shared by projections from both eyes.

Conclusions: Comparing these results to previous studies on the visual systems of scorpions and other chelicerates, we found striking similarities to the innervation pattern in Limulus polyphemus for both median and lateral eyes.

This supports from a visual system point of view at least a phylogenetically basal position of Scorpiones in Arachnida, or even a close relationship to Xiphosura. In addition, we propose a ground pattern for the central projections of chelicerate median eyes.
\end{abstract}

Keywords: Chelicerata, Scorpiones, Visual system, Central projections, Phylogeny

\section{Introduction}

Scorpions have two classes of eyes: one pair of large elevated eyes in the middle of the carapace commonly referred to as median eyes, and two to five pairs of small eyes along the anterior, lateral margin of the carapace, commonly referred to as lateral eyes [1]. In both types, the eye is composed of a cuticular lens, photoreceptor cells, arhabdomeric cells, efferent neurosecretory fibres, and pigment cells. However, there are characteristic

\footnotetext{
* Correspondence: lehmann@zsm.mwn.de

'SNSB - Bavarian State Collection of Zoology, Münchhausenstraße 21,

Munich 81247, Germany

${ }^{2}$ Department Biology II, Ludwig-Maximilians-Universität München,

Großhaderner Straße 2, Planegg-Martinsried 82152, Germany

Full list of author information is available at the end of the article
}

differences in ultrastructure: in the lateral eyes the focusing lens and the vitreous body are lacking, and the rhabdomeres of all retinula cells form a contiguous rhabdom; median eyes, on the other hand, possess a focusing lens and a vitreous body, and the rhabdomeres of 4-6 retinula cells form separated star-shaped rhabdoms [2-4]. Additionally a pair of minute accessory lateral eyes have been demonstrated in prenymphs and nymphs of Parabuthus transvaalicus at the posterior end of the lateral eye row, and separated from these by a cuticular ridge [5]. These eyes are composed of photoreceptor cells, arhabdomeric cells and efferent neurosecretory fibres, but a cuticular lens and pigment granules are absent.

\section{Biomed Central}

(c) 2013 Lehmann and Melzer; licensee BioMed Central Ltd. This is an Open Access article distributed under the terms of the Creative Commons Attribution License (http://creativecommons.org/licenses/by/2.0), which permits unrestricted use, distribution, and reproduction in any medium, provided the original work is properly cited. 
The median eyes are the scorpion's main eyes, allow good image processing with relatively high acuity and good spatial discrimination, and exhibit a distinct circadian sensitivity rhythm [3]. In lateral eyes, due to the construction of the dioptric apparatus as well as the anatomy of the retina, the visual acuity is reduced. They have been suggested to function mainly as extremely sensitive light detectors, e.g. for Zeitgeber stimuli to synchronize a circadian clock $[3,4]$. The neurobiology of this circadian clock is well known for the North African desert scorpion, Androctonus australis (see summary by Fleissner [6]).

So far, the visual systems of scorpions have been studied mainly in a neurophysiological context, whereas their morphological features are undescribed on a level that would allow phylogenetic comparisons [7-9]. Holmgren [7] suggested a series of four visual neuropils ("Seemasse 1-4"), with the median eyes linked to the first and the lateral eyes to the second neuropil. Holmgren's pupil, Hanström [8], identified the same neuropils, but distinguished between median and lateral eye neuropils and suggested that the median eyes are linked to one neuropil and the lateral eyes to three subsequent neuropils, while some fibre bundles project from the median eye neuropil to the third lateral eye neuropil. Fleissner [9] reported that the photoreceptor cell axons of the median eyes terminate within a first neuropil ("lamina"), while the axons of the arhabdomeric cells terminate in a second neuropil ("medulla"); the retinula cell axon terminals of the lateral eyes were not defined.

Lately the structure and development of various nervous systems have played important roles in debates concerning arthropod evolution and phylogeny. For this field of research two different approaches "neurophylogeny" $[10,11]$ and "neural cladistics" [12] - were established.

In Chelicerata other than Scorpiones, especially well studied visual systems are that of the xiphosuran Limulus polyphemus [13-16], which is an important, well investigated species in the field of visual neuroscience, and those of several Araneae [17-20] (Salticus scenicus, Habrocestum pulex, and Cupiennius salei). Recent investigations addressed visual systems in Pycnogonida [21] (Achelia langi, A. vulgaris, and Endeis spinosa), the sister taxon to Euchelicerata or even to Euarthropoda, and in Onychophora [22,23] (Euperipatoides rowelli, Epiperipatus biolleyi, and Metaperipatus blainvillei), a putative arthropod outgroup.

The phylogenetic position of Scorpiones was discussed in various ways over the last one hundred years: Analysis based on morphological data either saw Scorpiones as highly ancestral Arachnida and as the sister taxon to Lipoctena ( $=$ all other arachnids) [24], or grouped Scorpiones together with Opiliones, Pseudoscorpiones, and Solifugae, to form the arachnid subgroup of Dromopoda [25]. Recently five arachnid clades were proposed, one of them being the clade Stomothecata comprising Scorpiones and Opiliones, but the relationships between those 5 clades is unresolved [26]. Combined morphological and molecular analyses support Dromopoda [27,28]. Also in molecular studies, the phylogenetic position of scorpions is interpreted in different ways $[29,30]$. And lastly some palaeontologists continue a long tradition of placing scorpions outside Arachnida with Eurypterida [31,32]. Eurypterida (the sea scorpions) is the extinct sister taxon to Xiphosura, with which it forms the group Merostomata.

To make the visual system in scorpions accessible for phylogenetic comparison with those in other chelicerates, the present study employs several independent approaches (3D serial reconstruction, Cobalt fills, DiI / DiO labelling, Wigglesworth stains). In the scorpion species Euscorpius italicus (Herbst, 1800) and E. hadzii Di Caporiacco, 1950, the visual neuropils of the median and lateral eyes are identified with Cobalt fills and DiI / DiO labelling, and their general architecture is studied along with the termination sites of retinula cell axons. Additionally the main neuropils of the protocerebrum are described by means of osmiumethyl gallate procedure and AMIRA 3D-reconstruction. This reveals features of the visual system generally studied in Chelicerata, to allow comparisons with other lineages.

\section{Results}

\section{General layout of the visual system}

The visual system in the studied scorpion species, Euscorpius italicus and E. hadzii, is composed of two median eyes located medially on top of the cephalothorax, and two pairs of lateral eyes located along the front corners of the cephalothorax. Nerve fibres project from the median and lateral eyes proximally to the dorso-lateral protocerebrum. The two median eyes supply two distinct, successive visual neuropils as targets of the R-cell axons; few fibres additionally connect the median eyes with the arcuate body (Figure 1). The first neuropil is located dorso-anteriorly in the lateral part of the protocerebrum, as an oval-shaped region laterally embedded in the cell body rind of the brain (Figure 1A). The second neuropil lies deeper, under the cell body rind and in a more ventral and lateral position in the protocerebrum (Figure 1B-F).

The two lateral eyes also supply two distinct, successive visual neuropils as targets of the R-cell axons (Figure 2). The second visual neuropils of the median and lateral eyes overlap each other; this means that some R-cell axons of the median and lateral eyes end in a shared region of the second visual neuropil (Figures 3, 4). The first neuropil is located in the lateral and anterior part of the protocerebrum, $50-100 \mu \mathrm{m}$ ventrally underneath the 


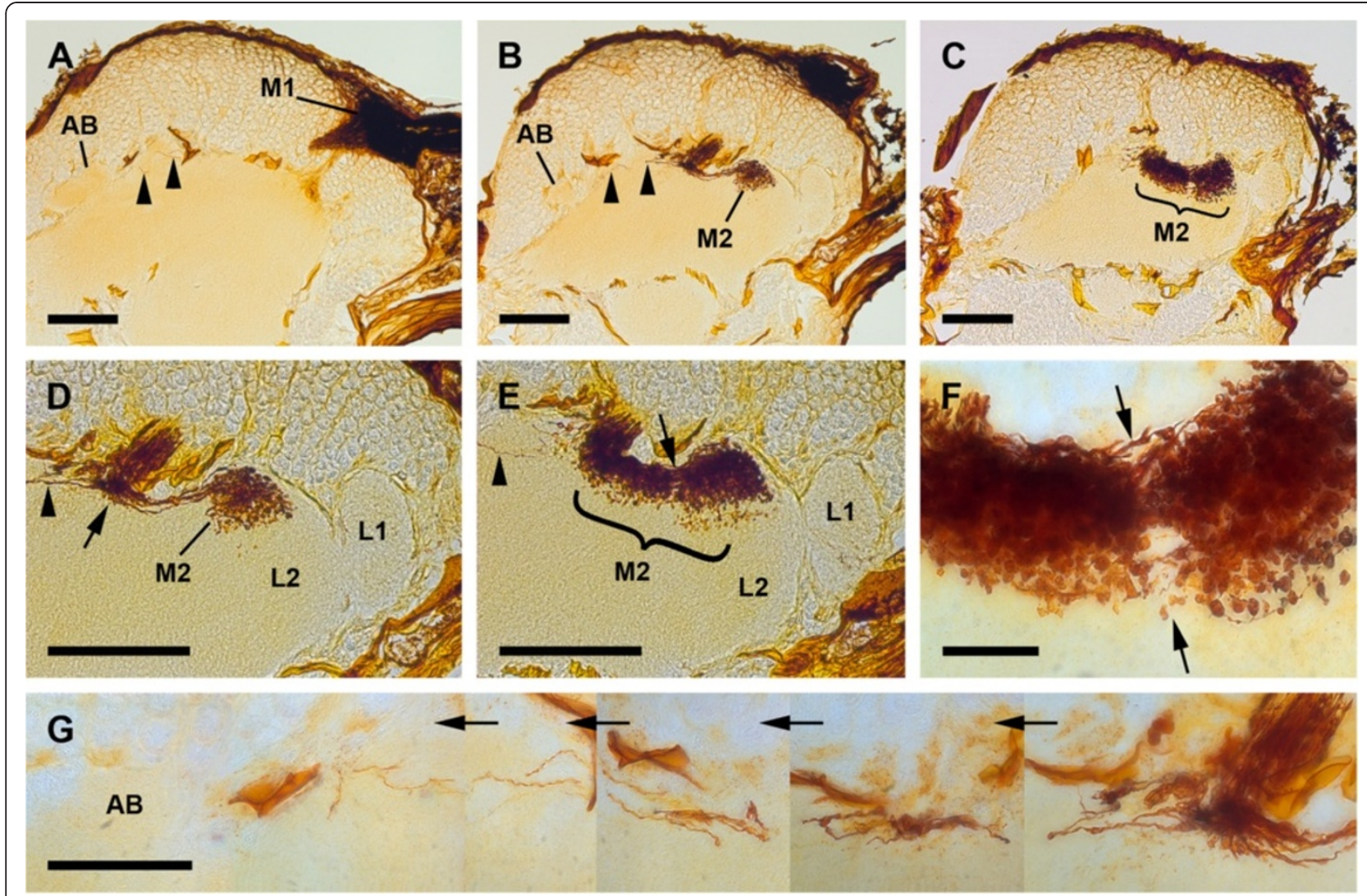

Figure 1 Cobalt fills via median eyes, sagittal sections. A, first median eye visual neuropil posteriorly in dorso-lateral protocerebrum. Note dense arrangement of Cobalt-filled profiles. Arrowheads point to axons extending to arcuate body. Bar $100 \mu \mathrm{m}$. B, bifurcation of fibres projecting from first to second median eye neuropil. Arrowheads point to axons extending to arcuate body. Bar $100 \mu \mathrm{m}$. C, second median eye visual neuropil under cell body rind, divided by an annulus into posterior and anterior subunit. Bar $100 \mu \mathrm{m}$. D, detail of bifurcation, varicosities in anterior subunit of second median eye visual neuropil. Arrowhead points to axons extending to arcuate body. Bar $100 \mu \mathrm{m}$. E, detail of second median eye visual neuropil, showing varicosities in both subunits. Arrowhead points to axons extending to arcuate body. Bar $100 \mu \mathrm{m}$. F, detail of annulus (arrows). Bar $25 \mu \mathrm{m}$. G, combination of five successive sections to demonstrate path of Cobalt-filled axons connecting median eyes with arcuate body via bifurcation seen in B and D. Bar $50 \mu \mathrm{m}$. AB, arcuate body; L1, first lateral eye visual neuropil; L2, second lateral eye visual neuropil; M1, first median eye visual neuropil; M2, second median eye visual neuropil.

first visual neuropil of the median eyes. It is oval, and laterally embedded in the cell body rind of the brain (Figure 2A-C). The second neuropil lies posterior to the first neuropil and is also oval (Figure 2D, E).

The visual neuropils are unequivocally identified with Cobalt fills and DiI / DiO labelling (Figures 1, 2, 3 and 4), and can also be recognised with osmium-ethyl-gallate staining (Figure 5), as dark-stained areas, as is typical for dense neuropils such as sensory neuropils. The third target region, i.e. that of the median eyes in the vicinity of the arcuate body, is also identified with both, Cobalt fills and DiI / DiO labelling (Figures 1, 4).

Furthermore, the arcuate body occupies a superficial, dorso-posterior position in the brain; its shape is slightly bent anteriorly (Figure 5F). The mushroom bodies are located parallel to the midline on each side of the protocerebrum (Figure 5D, E). Both neuropils can be recognised with osmium-ethyl-gallate staining.

\section{Cobalt fills and Dil labelling via median eyes}

Both methods of staining via the median eyes reveal two distinct retinula axon target regions in each hemisphere of the protocerebrum, a first and a second visual neuropil (Figures 1, 4A-C). Furthermore, fibres attributed to visual neurons connect the median eyes with the arcuate body (Figures 1, 4A-C).

Cobalt fills: Immediately after entering the brain the retinula axons build synaptic varicosities all over their extension within the neuropil (Figure 1A). After the first neuropil the retinula axons project ventro-posteriorly in a tract through the cell body rind deeper in the protocerebrum (Figure 1A, B). In this tract no synaptic varicosities appear. After passing through the cell body rind the axons diverge in two directions (Figure 1B, D). The larger parts of the axons first make a U-turn, then project anteriorly towards the visual neuropils of the lateral eyes (see below), while a few axons run further 


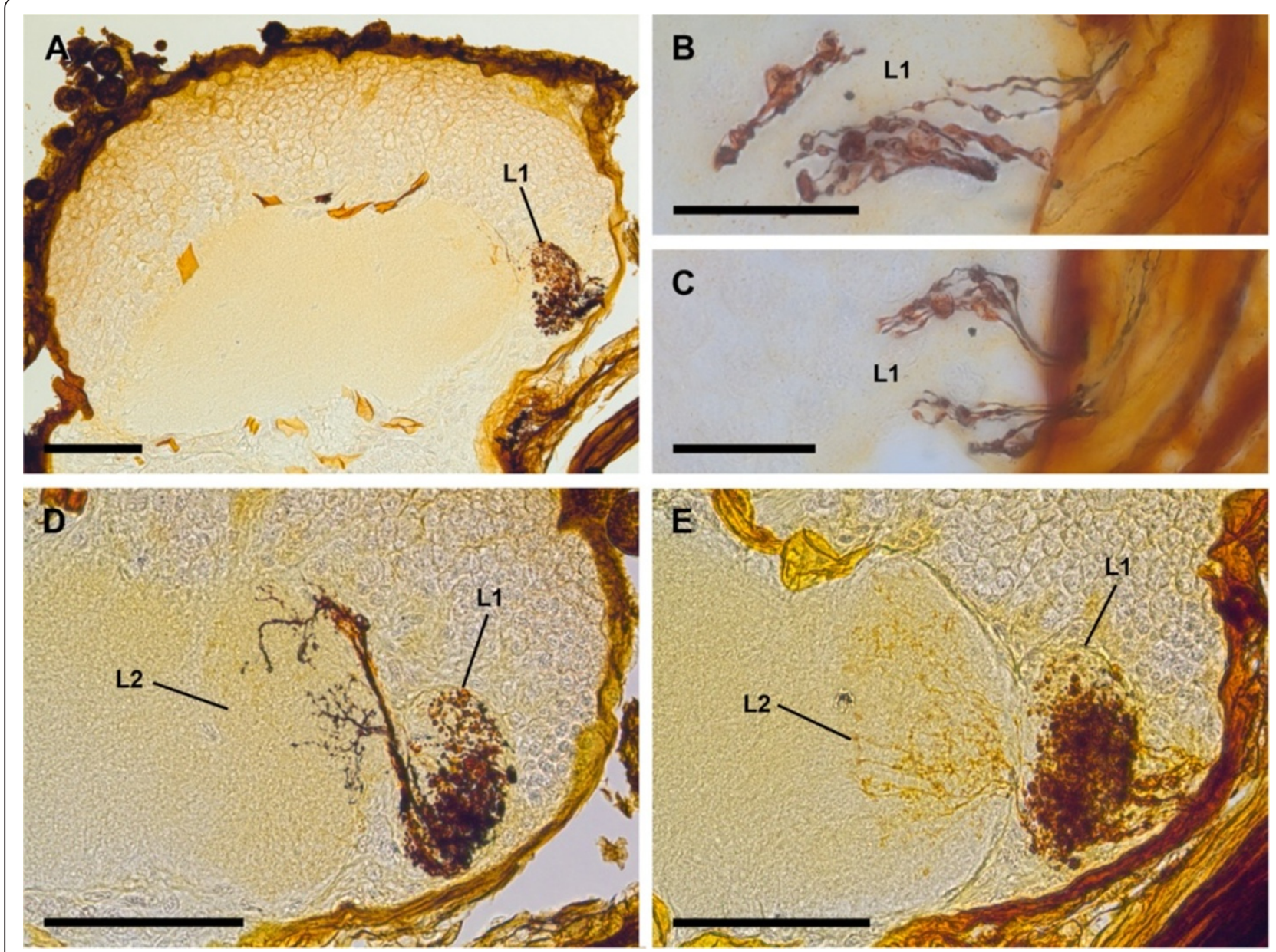

Figure 2 Cobalt fills via lateral eyes, sagittal sections. A, first lateral eye visual neuropil posteriorly in ventro-lateral protocerebrum. Note dense arrangement of Cobalt-filled profiles. Bar $100 \mu \mathrm{m}$. B, C, details of Cobalt-filled retinula axons with varicosities at entrances to first lateral eye visual neuropil. Bars $25 \mu \mathrm{m}$. D, E, Cobalt fills of retinula axons terminating in first and second lateral eye visual neuropils. Note that some fibres seem to cross between first and second visual neuropils. Bars $100 \mu \mathrm{m}$. L1, first lateral eye visual neuropil; L2, second lateral eye visual neuropil.

posteriorly to the vicinity of the arcuate body - which lies dorso-posteriorly in the protocerebrum - without entering the arcuate body directly (Figure 1A, B, D, E, G). These posterior-running fibres connecting the median eyes with the arcuate body were observed in a few specimens only. Immediately after the bifurcation, about half a dozen fibres with few synaptic varicosities are visible, but only one or two fibres are Cobaltfilled as far as the vicinity of the arcuate body. This might have resulted from experimental diffusion times $(1-4 \mathrm{~h})$ too short for such a long distance (approx. $300 \mu \mathrm{m})$. The anteriorly running fibres end in the second visual neuropil (Figure 1B-F). This neuropil lies underneath the cell body rind and is split in two subunits, an anterior and a posterior one, divided by an annulus (Figure 1E, F). Synaptic varicosities occur in both subunits. The anterior subunit lies in the dorsal part of the second visual neuropil of the lateral eyes (see below).
DiI labelling: The same target regions identified with Cobalt fills could be labelled with DiI (Figure 4A-C). After the first neuropil the retinula axons project ventro-posteriorly and diverge in two directions. The larger parts of the axons project to the second neuropil, while few fibres attributed to visual neurons run further posteriorly to the arcuate body. The morphology of the second visual neuropil is very similar to that visible in the Cobalt fills (Figure 4B). Again the neuropil is composed of two subunits divided by an annulus. However, the two subunits extend more ventrally; in the Cobalt fills, synaptic varicosities of the anterior subunit can be found only in the dorsal part of the second visual neuropil of the lateral eyes, while with DiI labelling synaptic varicosities can be found throughout this neuropil. This may be a result of the long diffusion time and hence of transcellular labelling. The fibres running posteriorly towards the arcuate body can be identified with DiI labelling as well. Synaptic varicosities after the bifurcation are 


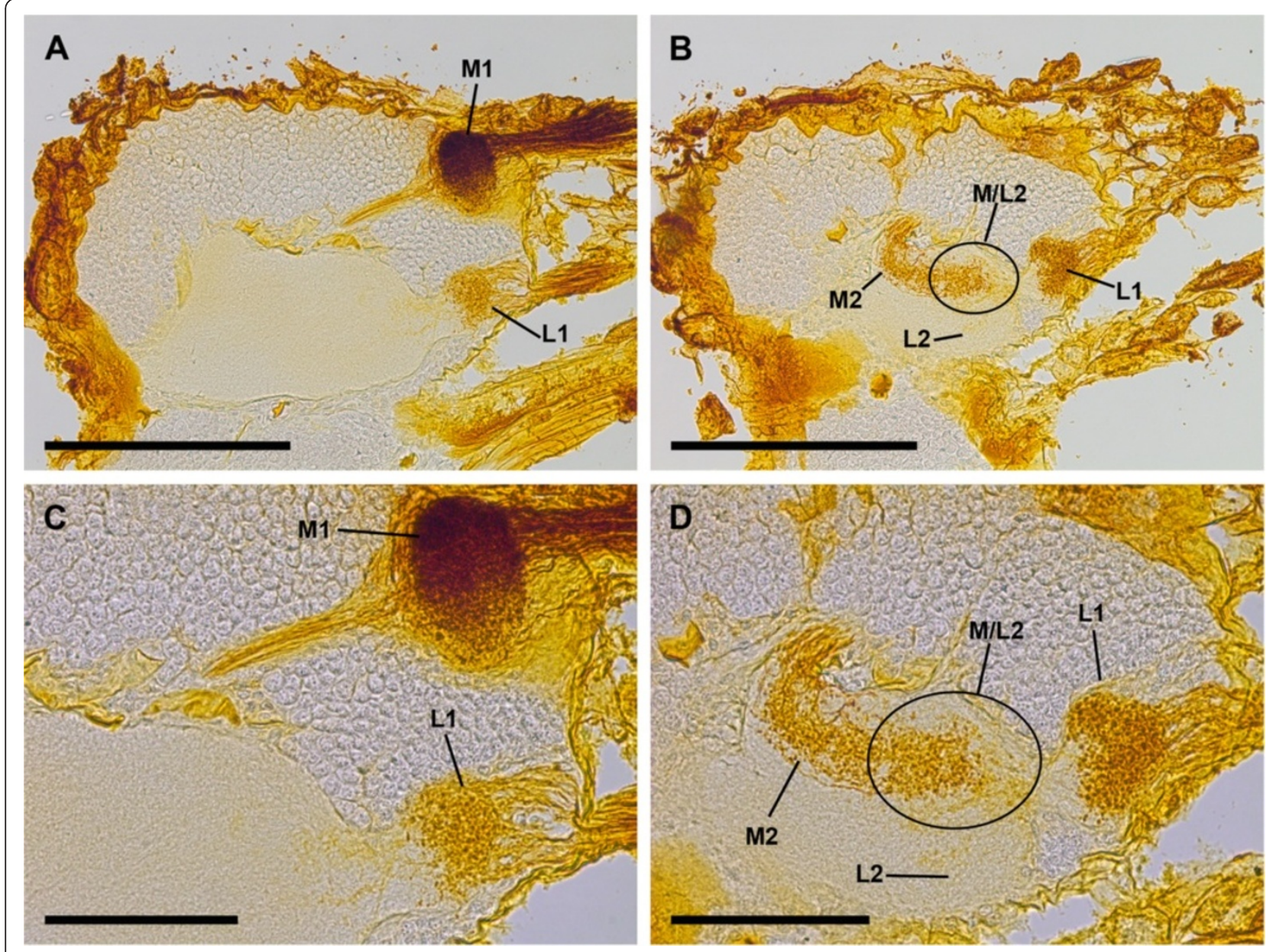

Figure 3 Cobalt fills simultaneously via median and lateral eyes, sagittal sections. A, first median and lateral eye visual neuropils, located posteriorly in lateral protocerebrum. Both neuropils with Cobalt-filled retinula axons. Bar $250 \mu \mathrm{m}$. B, second visual neuropils of median and lateral eyes. Besides regions with only Cobalt-filled R-cell axons of median or lateral eyes, encircled region with Cobalt-filled R-cell axons of both median and lateral eyes. Bar $250 \mu \mathrm{m}$. C, detail of first median and lateral eye visual neuropils. Note tract through cell body rind projecting to second median eye visual neuropil. First varicosities appear posterior to first lateral eye visual neuropil, indicating second lateral eye visual neuropil. Bar $100 \mu \mathrm{m}$. D, detail of second visual neuropils of median and lateral eyes. One can distinguish between lateral and median eye fills, lateral fills brighter. Besides regions with only Cobalt-filled R-cell axons of median or lateral eyes, encircled region with Cobalt-filled R-cell axons of both median and lateral eyes. Bar 100 Mm. L1, first lateral eye visual neuropil; L2, second lateral eye visual neuropil; M1, first median eye visual neuropil; M2, second median eye visual neuropil; M/L2, region of L2 or M2 with Cobalt-filled R-cell axons of both median and lateral eyes.

better recognisable than in the Cobalt fills. Furthermore, the axons are labelled all the way through the arcuate body, the pale labelling resulting from the fact that only few axons are present in this area (Figure 4A).

\section{Cobalt fills via lateral eyes}

Cobalt fills via the lateral eyes also reveal two distinct retinula axon target regions in each hemisphere of the protocerebrum, a first and a second visual neuropil (Figure 2).

After entering the first visual neuropil the retinula axons build synaptic varicosities all over their extensions (Figure 2A-C). A chiasma between the first and second visual neuropils is not positively identified in any of the chosen section planes (sagittal, frontal or transversal), but fibres that seem to cross between first and second visual neuropil are observed (Figure 2D, E).

In the second visual neuropil the retinula axon terminals are branched and have synaptic varicosities (Figure 2D, E). In the dorsal region of this neuropil terminals of the retinula axons of the median eyes are observed in preparations in which retinula axons of both median and lateral eyes are Cobalt-filled (Figure 3B, D) (see below).

\section{Cobalt fills and Dil / DiO labelling simultaneously via median and lateral eyes}

As above the median eyes are directly linked to a first and a second neuropil, and connected to the arcuate 

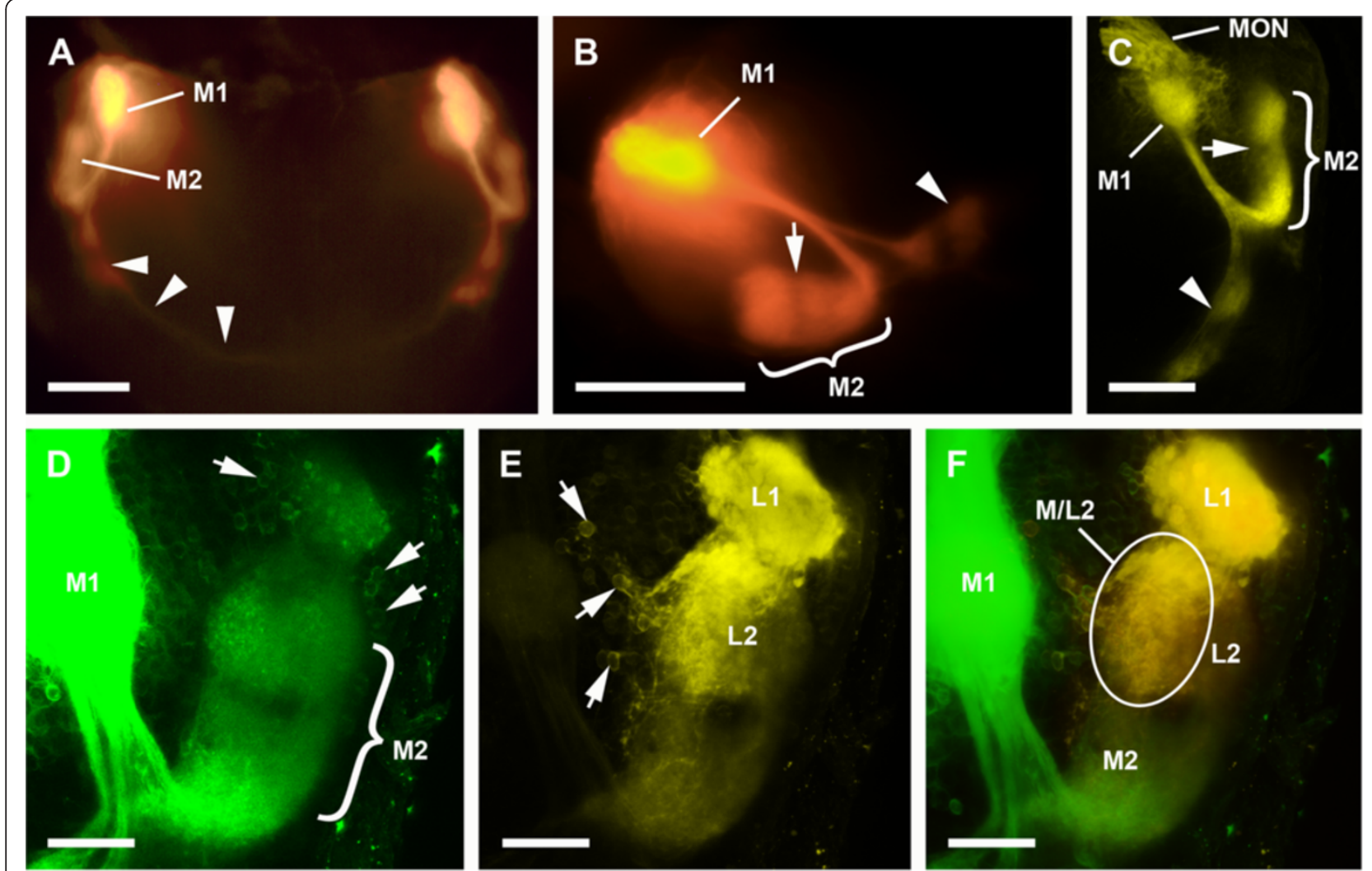

Figure 4 Dil and DiO labelling via median or median and lateral eyes (A, B, fluorescence microscope; C-D, CLSM). A, B, Dil-labelled first and second median eye neuropils. Arrowheads point to axons extending to arcuate body with varicosities after bifurcation, few axons terminating within the arcuate body. Note same annulus as seen in Cobalt fills (arrow). A, frontal view; B, sagittal view. Bars $200 \mu$ m. C, Specimen as in A, B, studied with CLSM. Frontal view. Bar $100 \mu \mathrm{m}$. D-E, Combined DiO-labelled median (green) and Dil-labelled lateral (yellow) eye neuropils. Frontal view. Bars $50 \mu \mathrm{m}$. D, DiO-labelled first and second median eye neuropils (green). Note that DiO-stained cell bodies (arrows) indicate transcellular staining. E, Dil-labelled first and second lateral eye neuropils (yellow). Note that Dil-stained cell bodies (arrows) indicate transcellular staining. F, Combined image of DiO-labelled median (green) and Dil-labelled lateral (yellow) eye neuropils. Encircled region of second median and lateral eye neuropils with labelled R-cell axons of both median and lateral eyes. L1, first lateral eye visual neuropil; L2, second lateral eye visual neuropil; M1, first median eye visual neuropil; M2, second median eye visual neuropil; M/L2, region of L2 or M2 with labelled R-cell axons of both median and lateral eyes; MON, median eye optic nerve.

body (Figures 1, 3, 4), the lateral eyes are linked to a first and a second neuropil (Figures 2, 3, 4E ,F).

Cobalt fills: The second visual neuropils of median and lateral eyes overlap each other. This means that besides the regions with only Cobalt-filled R-cell axons of median or lateral eyes, there is a region with Cobaltfilled R-cell axons from both median and lateral eyes (Figure 3B, D).

$\mathrm{DiI} / \mathrm{DiO}$ labelling: The second visual neuropils of median and lateral eyes overlap each other, and the same region with R-cell axons from both median and lateral eyes can be identified with DiI labelling via lateral eyes and with DiO labelling via median eyes (Figure 4E). DiIand DiO-labelled cell bodies in the cell body rind near the neuropils indicate that transcellular labelling occurred (Figure 4D-E). Hence, in contrast to the Cobalt fills, where no transcellular staining occurred, $\mathrm{DiO}$ from the median eyes is identifiable even in the first lateral eye neuropil, and DiI from the lateral eyes even in the posterior subunit of the second median eye neuropil.

Figure 6 shows the summary of the retinula axons and visual neuropils of the median and lateral eyes in $E$. italicus.

\section{Discussion}

The present study constitutes another case that a comparison of more recent findings with those of the early 20th century neuroanatomists, Nils Holmgren [7] and Bertil Hanström [8] is worthwhile. The latter authors correctly identified the visual neuropils of scorpions, but misinterpreted the tracts between them. Holmgren described the same neuropils as Hanström, but did not differentiate between median and lateral eye neuropils. Holmgren's first and fourth visual neuropils actually are median eye neuropils, his second and third neuropils are lateral eye neuropils. Hanström made this differentiation, 

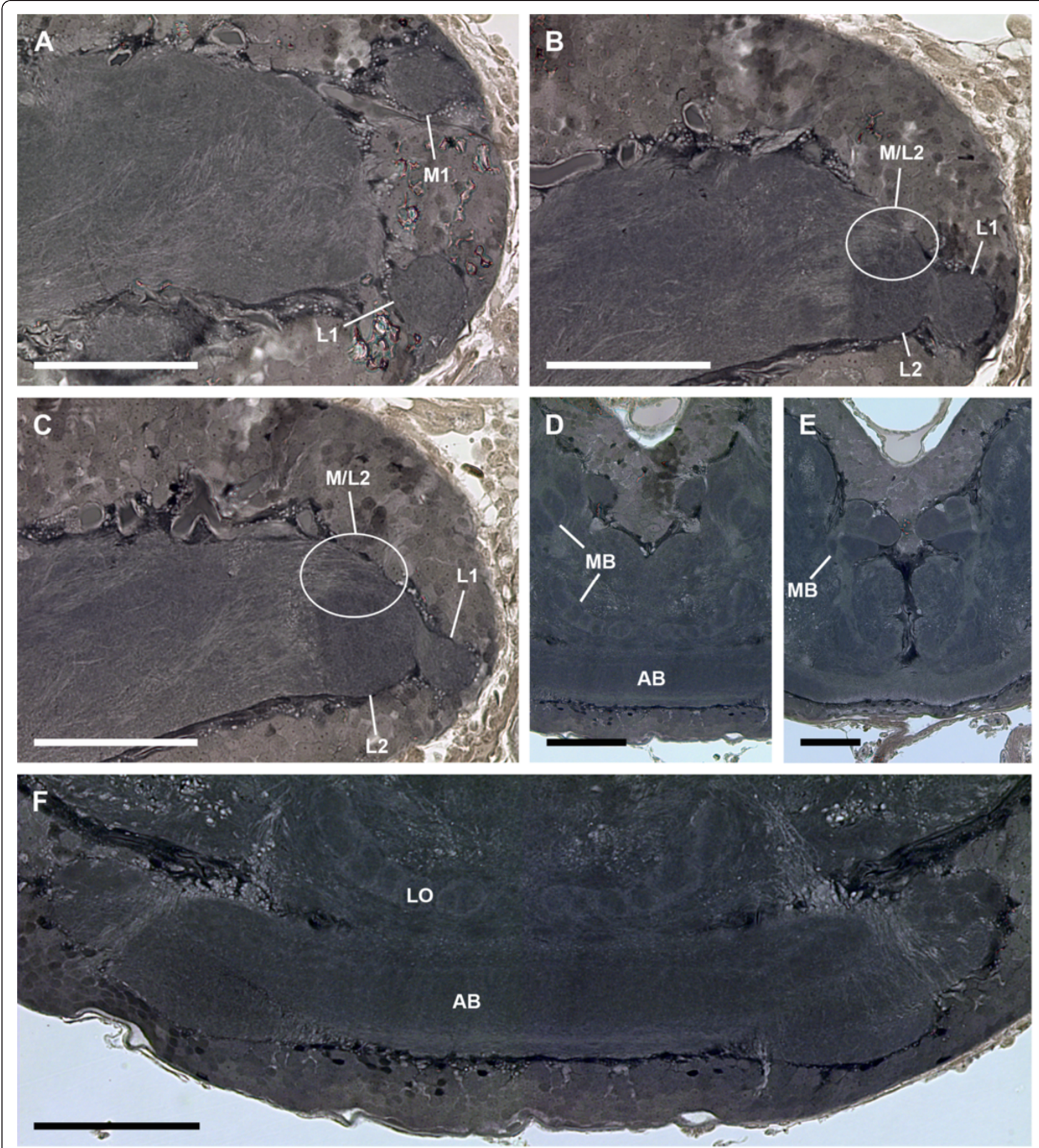

Figure 5 General anatomy of visual neuropils and protocerebrum (Wigglesworth stains). Note dark stain of sensory neuropils after application of Wigglesworth's technique. Bars $100 \mu \mathrm{m}$. A, first visual neuropils of median and lateral eyes, sagittal section. B, C, first and second visual neuropils of lateral eyes. Encircled: region where also R-cell axons of median eyes terminate, sagittal sections. $\mathbf{D}, \mathbf{E}$, mushroom bodies located parallel to midline of protocerebrum, frontal section. $\mathbf{F}$, arcuate body in dorso-posterior position, frontal section. AB, arcuate body; L1, first lateral eye visual neuropil; L2, second lateral eye visual neuropil; M1, first median eye visual neuropil; M2, second median eye visual neuropil; $M / L 2$, region of $L 2$ or $M 2$ with Cobalt-filled R-cell axons of both median and lateral eyes; MB, mushroom bodies.

but contrary to what he suggested, the median eyes are associated with two subsequent visual neuropils (not only with one), and the lateral eyes are associated with two subsequent visual neuropils (not with three). Hanström described a tract connecting the median eye neuropil with a third lateral eye visual neuropil. In our 

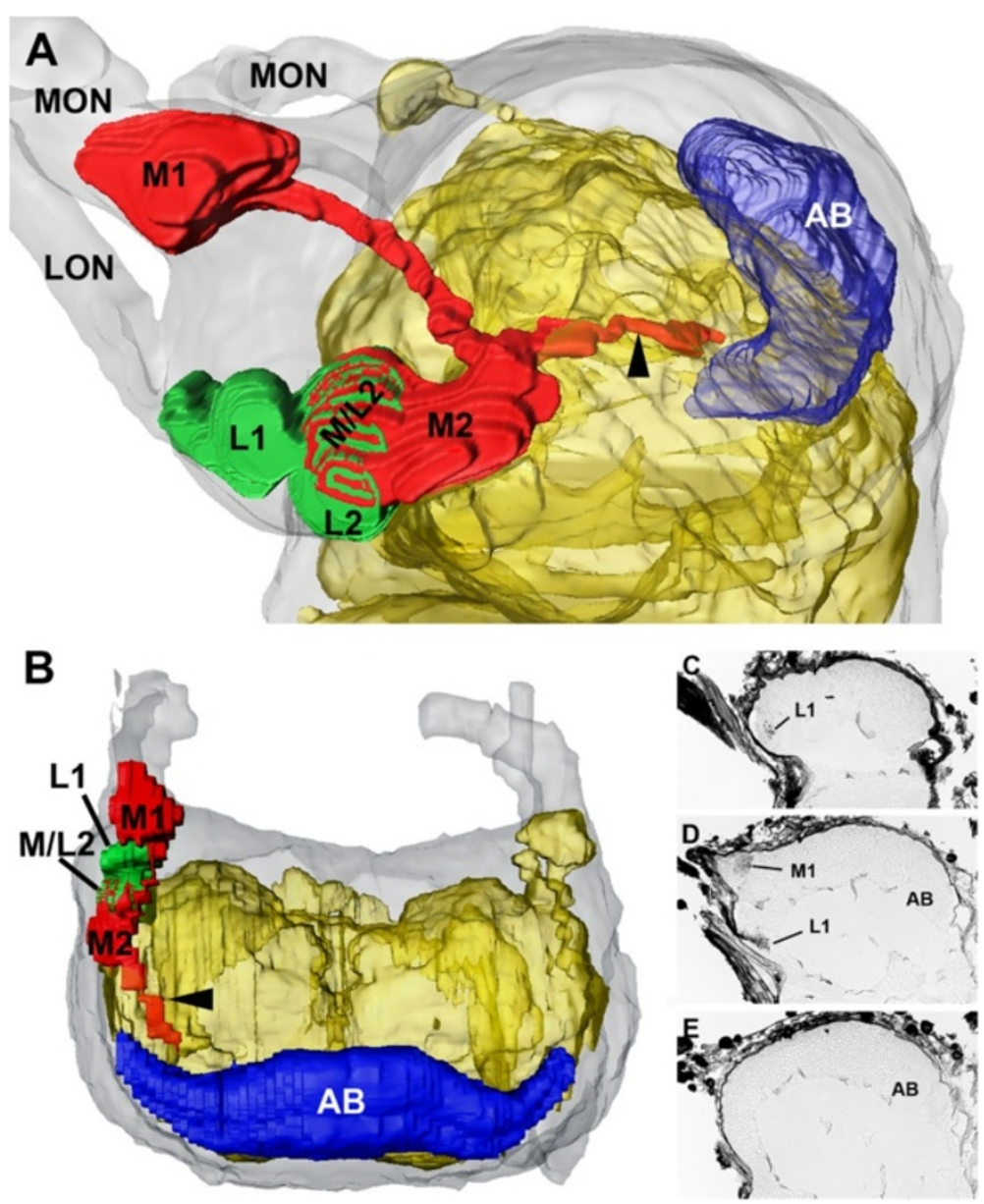

Figure 6 3D serial reconstruction of visual system of left hemisphere in E. italicus on the basis of Cobalt fills. A, B, 3D reconstruction showing arrangement of neuropils. A, lateral view; B, frontal view. Grey, protocerebrum; yellow, neuropil; red, median eye neuropils; green, lateral eye neuropils; blue, arcuate body. C-E, three selected sections (Cobalt fills) showing original data for reconstruction. $\mathbf{C}$, parasagittal section showing beginning of first lateral eye visual neuropil. D, parasagittal section showing first median and lateral eye visual neuropils, and beginning of arcuate body. $\mathbf{E}$, mid-sagittal section without visual neuropils but with arcuate body. AB, arcuate body; LON, lateral eye optic nerve; L1, first lateral eye visual neuropil; L2, second lateral eye visual neuropil; MON, median eye optic nerve; M1, first median eye visual neuropil; M2, second median eye visual neuropil; M/L2, region of L2 or M2 with Cobalt-filled R-cell axons of both median and lateral eyes.

results that tract is the one connecting the first with the second median eye neuropil; Hanström may have been misled by the position of the second median eye neuropil to misinterpret the latter as a third lateral eye neuropil. In addition, a connection between the visual system and the arcuate body was observed by both authors, which can be confirmed here.

Our results show that the median eye retinula cells are linked to a first and a second visual neuropil, while some fibres additionally connect the median eyes with the arcuate body. The lateral eye retinula cells are linked to a first and a second visual neuropil as well. Furthermore, our stainings show that there is a region in which the second median and second lateral eye neuropils overlap each other. One can distinguish three regions (from posterior to anterior): (1) a region with $\mathrm{R}$-cell axon terminals of median eyes only, (2) a region with R-cell axon terminals of both, median and lateral eyes, and (3) a region with R-cell axon terminals of lateral eyes only. This division is particularly evident in the Cobalt fills. In the DiI and DiO labelling transcellular staining occurred. The latter is recognisable by the fact that cell bodies of interneurons are labelled. Hence, the division of these three regions is visible but not as distinct as in the Cobalt fills, where no transcellular staining occurred. There are three alternative ways to describe and name these regions. One may consider this region as one neuropil, as two neuropils overlapping each other, or as three neuropils (one median, one median/lateral, and one lateral eye visual neuropil). We prefer the second alternative and consider this region as two neuropils, one second median eye neuropil and one second lateral eye neuropil, which partly overlap each other. This means that there is a region with R-cell axons of both median 
and lateral eyes, but in both second visual neuropils there are also regions with only retinula axon terminals of median or lateral eyes. Moreover, the retinula axon terminals of the lateral eyes are described here for the first time: R-cell axon terminals are found in a first and a second lateral eye neuropil. The crossing fibres we observed probably do not represent a "classical" chiasm as found in Tetraconata [12,33]. A detailed analysis is needed to find out if it might correspond to the chiasm in Limulus, which is suggested to be convergent to that in Tetraconata [15,34].

The only other more recent surveys considering the morphology of the visual systems in scorpions were made by Fleissner [9] and Heinrichs and Fleissner [35]. These studies discussed mainly the electrophysiology of the scorpion visual system, and gave only schematic drawings of the approximate locations of the visual neuropils without identifying the latter. However, Fleissner [9] and Heinrichs and Fleissner [35] did report that the different cell types of the median eye retina have different target regions: the photoreceptor cells terminate in a first neuropil (lamina), the arhabdomeric cells in a second neuropil (medulla) [9], while the efferent neurosecretory fibres have their origin/cell body in the tritocerebrum and terminate, while passing through the arcuate body, in the retina of the median eyes [35]. The target region of the photoreceptor cells is located where we found the first median eye neuropil, and the target region of the arhabdomeric cells is where we found the second median eye neuropil; the pathways of the neurosecretory fibres are equal to the fibres we found that connect the median eyes with the arcuate body. Such differentiation of target regions of the different cell types could not be achieved with the methodology chosen for the present study, but will be considered in the discussion below.

Thus our study, while taking the results of Fleissner and Heinrichs into account, leads to a new interpretation of the visual system as well as of the general architecture of the scorpion protocerebrum. The median eyes are associated with two serial neuropils, a first and a second visual neuropil, while some fibres connect the median eyes with the arcuate body. The second visual neuropil is subdivided by an annulus; the posterior subunit contains only retinula axon terminals of the median eyes, while the anterior subunit contains retinula axon terminals of both median and lateral eyes. Furthermore, Fleissner [9] showed that the first neuropil is the target region of the photoreceptor cells, and the second visual neuropil that of the arhabdomeric cells. The morphology of the fibres projecting to the arcuate body is very similar to that of the efferent neurosecretory fibres described by Heinrichs and Fleissner [35]. The authors identified efferent neurosecretory fibres with cell bodies in the tritocerebrum projecting through the arcuate body to the retina of the median eyes. Hence, the fibres projecting to the arcuate body, observed here in Cobalt and DiI stains, are rather retrograde-filled axons projecting from the tritocerebrum through the arcuate body to the retina of the median eyes. Due to the fact that these cells have their cell bodies in the tritocerebrum, they rather "belong" to the brain and are not retinula cells.

The lateral eyes are associated with two serial neuropils, a first and a second visual neuropil. Retinula axon terminals occur in both neuropils, while in the dorsal part of the second visual neuropil retinula axon terminals of both lateral and median eyes are observed.

The slightly bent arcuate body is shown in a superficial, dorso-posterior position in the brain, as is typical for chelicerates [36]. Additionally the mushroom bodies can be observed, located parallel to the midline of the protocerebrum.

These highly specific features described in the present study allow a comparison with the visual systems in other chelicerates and in ancestral arthropods.

\section{Median eyes}

In Limulus one must distinguish between the paired median eyes and the fused median rudimentary eye (see review by Battelle [16], and Table 1). Chamberlain and Barlow [13] demonstrated by means of Cobalt fills that the median optic nerve, which contains fibres from both, the paired median eyes and the fused median rudimentary eye, is linked to the first median eye neuropil (ocellar ganglion), arcuate body, optic tract, and medulla (which is also the second lateral eye neuropil). Additionally Calman et al. [14] and Battelle [16] showed with antibody staining that the photoreceptor cells of the paired median eyes are linked in each brain hemisphere only to the first median eye neuropil (ocellar ganglion). Moreover, the authors derived the projections of the arhabdomeric cells by subtracting the photoreceptor cell projections from the results of Cobalt fills of the median eye nerve in Chamberlain and Barlow [13]. According to Calman et al. and Battelle the arhabdomeric cells end only in the medulla (second neuropil of the lateral eyes), but if one compares the results of Calman et al. [14] and Battelle [16] with those of Chamberlain and Barlow [13] one can see that Calman et al. and Battelle ignored that numerous collaterals can be found not only in the medulla (second lateral eye neuropil) but also in the optic tract before entering the medulla. Hence, one can see the target region of the arhabdomeric cells as a neuropil of its own that partly overlaps with the medulla (second lateral eye neuropil). This situation is very similar to the situation found here for the median eyes of scorpions: the second visual neuropil as a target of the 
Table 1 Distribution of eyes in Onychophora and Chelicerata [1,5,16,22,37]

\begin{tabular}{|c|c|c|}
\hline & Median eyes & Lateral eyes \\
\hline Onychophora & \multicolumn{2}{|c|}{ One pair of eyes (median/lateral affinity unknown) } \\
\hline Pycnogonida & Four & Absent \\
\hline Xiphosura & One pair, plus one fused median rudimentary eye & One pair of lateral compound eyes, plus one pair of lateral rudimentary eyes \\
\hline Scorpiones & One pair & Three to five pairs, plus one pair of nymphal eyes \\
\hline Araneae & One pair (= principal eyes or anterior median eyes) & Three pairs (= secondary eyes) \\
\hline
\end{tabular}

arhabdomeric cells partly overlaps with the second lateral eye neuropil as well.

Calman et al. [14] and Battelle [16] also demonstrated with biocytin injection and myosin III immunoreactivity that the fused median rudimentary eye of Limulus is linked in each brain hemisphere to the first median eye neuropil (ocellar ganglion) and simultaneously to a region near the arcuate body. This situation is similar to the median eyes of pycnogonids: their eyes are associated with a first visual neuropil and a second visual neuropil in close vicinity to the arcuate body [21]. However, the retinula axons of the fused median rudimentary eye in Limulus have some branches in both, the first median eye neuropil and the region near the arcuate body. In pycnogonids the retinula axons have branches only in the first or second visual neuropil, not in both neuropils simultaneously.

In Araneae there is only one target region of the retinula axon terminals of the median eyes (principal eyes or anterior median eyes): the first anterior median eye neuropil, located dorso-laterally in each brain hemisphere $[18,19]$. Subsequent second-order neurons terminate in a second visual neuropil (medulla); furthermore, a tract that extends into the arcuate body is suggested. Comparing the projections of the median eyes in scorpions with those of the anterior median eyes in Araneae, one finds similarities and differences. The photoreceptor cells project only to a bilaterally paired first visual neuropil. Furthermore, only photoreceptor cells and no arhabdomeric cells are described from the retinae of spiders. Hence, a connection from these cells to a second visual neuropil is missing.

Finally, in Onychophora (Euperipatoides rowelli) - one of the suggested sister taxa of Euarthropoda [38,39] whose brain organization is discussed as being similar to that in chelicerates $[23,40]$ - the presence of photoreceptor terminals in a first visual neuropil, which lies directly beneath the eye, is suggested [22]. From this first neuropil, an optic tract projects further and then bifurcates [23]. Its ventral branch extends to a second visual neuropil near the mushroom body calyces, while the dorsal branch gives rise to another second visual neuropil, which flanks the arcuate body laterally. The exact projection of the retinula cells is not identified unequivocally.
Thus, comparing the median eye visual system in scorpions to those in other chelicerates and in onychophorans, there are great similarities to the "normal" median eyes of xiphosurans, and some to the median rudimentary eyes of xiphosurans and median eyes of onychophorans, pycnogonids and spiders. As demonstrated in Lehmann et al. [21], the eyes of pycnogonids and the fused median rudimentary eye of Limulus, possibly also the eyes of onychophorans, show striking similarities in their innervation patterns.

The same is true for the median eyes of scorpions and Limulus. Both have two distinct, bilaterally paired target regions of the retinula cells: a first neuropil as target for the photoreceptor cells, and a second neuropil, which overlaps with the second neuropil of the lateral eyes, as target for arhabdomeric cells $[13,14]$.

\section{Lateral eyes}

Of special interest here are the eyes of Limulus, where one must distinguish again between the lateral rudimentary eyes and the lateral compound eyes (see review by Battelle [16], and Table 1). The rudimentary eyes are associated with the same neuropils as the lateral compound eyes, a first (lamina) and a second (medulla) visual neuropil; the second neuropil is also a target region of the arhabdomeric cells of the median eyes (see above) [14]. While the photoreceptor cells of the rudimentary eyes are linked to both, lamina and medulla, the photoreceptor cells of the lateral compound eyes are linked to the lamina only. Moreover, the retinae of the lateral compound eyes contain eccentric cells, which project to the lamina, medulla, optic tract, and to the first neuropil of the median eyes (ocellar ganglion).

Hence, the projections of the lateral eyes of scorpions have some characters in common with the lateral rudimentary eyes of Limulus. Like the lateral eyes of scorpions, the rudimentary eyes have projections to a first and a second visual neuropil. In turn, the photoreceptor cells in the lateral compound eye of Limulus are linked to the lamina only, while the eccentric cells are linked to the lamina and medulla of the lateral eye, optic tract, and to the first neuropil of the median eyes (ocellar ganglion). Such a connection from the lateral eye to median eye neuropils cannot be observed in the scorpion visual system. The similarity in function and structure between 


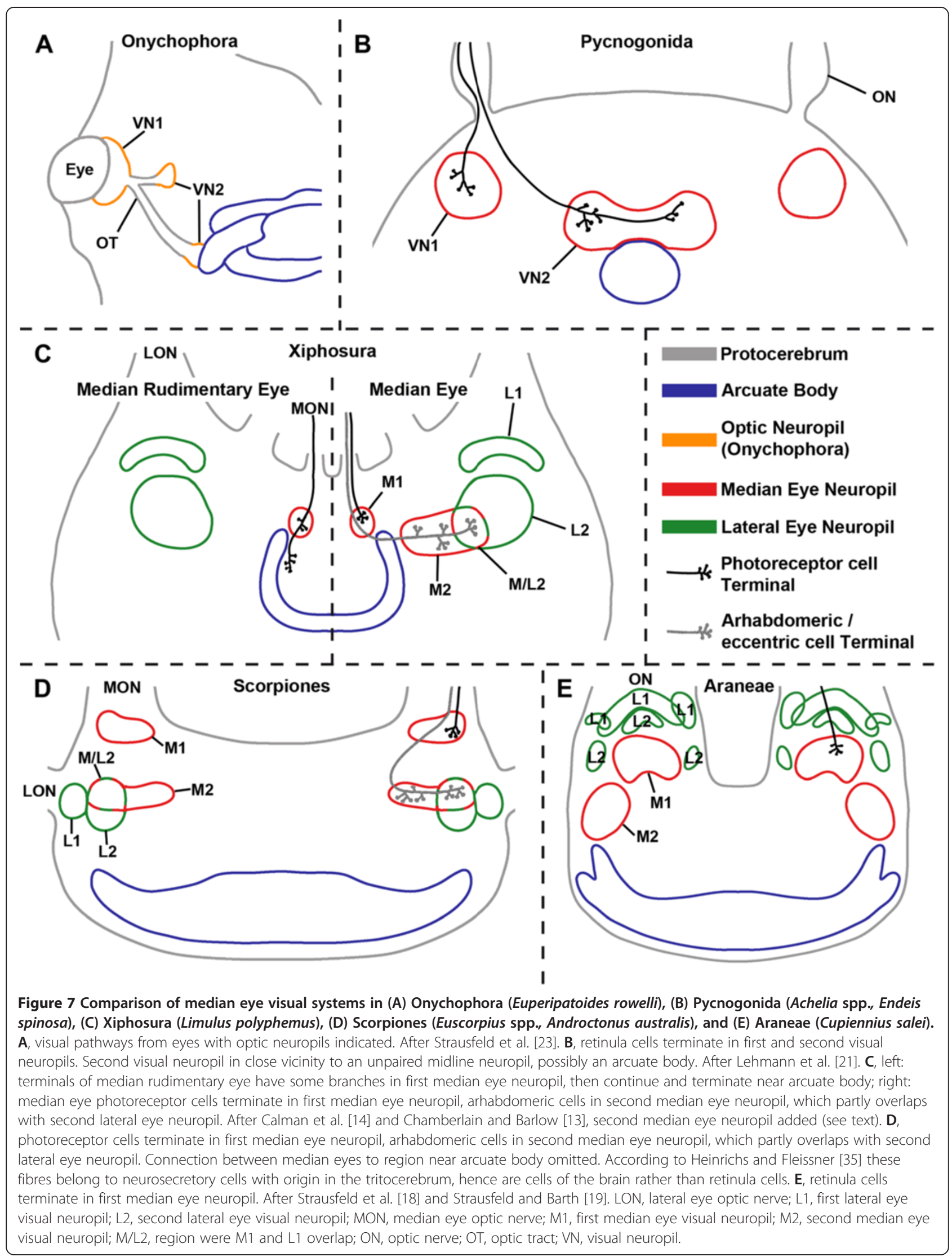


the eccentric cells and the arhabdomeric cells of scorpions was discussed by Schliwa and Fleissner [3,41]. More research has to be done to distinguish between the exact innervation patterns of the photoreceptor cells and the arhabdomeric cells in the lateral eyes of scorpions.

\section{Conclusions}

The large number of characters discussed in this article shows that the central projections of especially the median eyes in Chelicerata provide structures that are extremely useful for discussing aspects of chelicerate ground patterns and phylogenetic relationships. The sets of characters studied here for Scorpiones and those in Limulus, Pycnogonida, Onychophora, and Araneae are summarised in Figure 7.

As shown above, the similar innervation patterns of the median and lateral eyes indicate a close relationship concerning the visual system between scorpions and Limulus. Other characters supporting this idea are the position and cellular architecture of the accessory lateral eye of scorpions, which corresponds well with that of the lateral rudimentary eye of Limulus [5]. Also the functional and structural similarity of the arhabdomeric cells of scorpions with the eccentric cells of Limulus lateral eyes must be mentioned [3,41]. Dunlop and Webster [31] discuss further similarities between scorpions and Limulus. Besides similar sperm morphology and growth zones, the shared character of star-shaped rhabdoms is mentioned (see also Weygoldt and Paulus [24]). However, the argument of rhabdom morphology must be handled with care: indeed, scorpions and Limulus both have star-shaped rhabdoms, but this is only true for the lateral compound eyes of Limulus and the median but not the lateral eyes of scorpions. The latter have a net-like rhabdom [3]. Nevertheless, characters of the visual system support the hypothesis of Weygoldt and Paulus [24] that scorpions occupy the basalmost position within Arachnida, or even the idea of palaeontologists that Scorpiones are closely related to Eurypterida [31,32] and hence also to Xiphosura. This, in turn, would question the monophyly of Arachnida, and would mean that scorpions and one or more other arachnid lineages are likely to have come onto land independently [31]. More research concerning the visual systems in Arachnida has to be done, since only few taxa have been investigated, and there are no data on various taxa like Opiliones, Pseudoscorpiones, and Solifugae, which are suggested as sister taxa to Scorpiones by various authors [25-28].

Regarding the basal position of Limulus and especially Pycnogonida, it is reasonable to assume that the central projections of the median rudimentary eye in Limulus and the four median eyes in Pycnogonida represent the ground pattern for Chelicerata. This ground pattern is characterised by (1) four median eyes, (2) a separated, bilaterally paired nerve that connects the eyes with the brain, (3) a separated, bilaterally paired first visual neuropil with central projections of photoreceptor cells, (4) a second visual neuropil also with central projections of photoreceptor cells, and (5) the second visual neuropil being located in close vicinity to the arcuate body. Derived situations are found in the "normal" median eyes of Limulus and in the median eyes of scorpions: in both of these, the photoreceptor cells only project to a separated, bilaterally paired first visual neuropil, while the second type of retinula cells, the arhabdomeric cells, project to a second visual neuropil, which partly overlaps with the second visual neuropil of the lateral eyes. Additionally a third cell type is found in the retina of the median eyes, the efferent neurosecretory fibres, which have their origin/cell body in the brain and terminate in the retina. Another derived situation is found in the median eyes (principal eyes or anterior median eyes) of Araneae, whose photoreceptor cells (as the only cells in the retina projecting to the protocerebrum) simply project to a separated, bilaterally paired first visual neuropil.

\section{Materials and methods}

The use of Euscorpius spp. in the laboratory doesn't raise any ethical issues and therefore Regional or Local Research Ethics Committee approvals are not required.

\section{Specimen collection}

Specimens of Euscorpius italicus (Herbst, 1800) (Scorpiones: Euscorpiidae) were collected during field trips to Rovinj (Croatia) in August 2011 and April 2012. Specimens of Euscorpius hadzii Di Caporiacco, 1950 were provided by b.t.b.e. Insektenzucht $\mathrm{GmbH}$ (Schnürpflingen, Germany).

\section{Cobalt fills}

(Euscorpius italicus, modified after Altman and Tyrer [42]): $\mathrm{CoCl}_{2}$ crystals were inserted in median, lateral, or median and lateral eyes with a fine tungsten needle $(n=30)$. After diffusion times between 1 and 4 hours, Cobalt was precipitated with a solution of five drops of $\left(\mathrm{NH}_{4}\right)_{2} \mathrm{~S}$ in $10 \mathrm{ml}$ $\mathrm{H}_{2} \mathrm{O}_{\text {dest }}$. After fixation of the cephalothorax in AAF $(85 \mathrm{ml}$

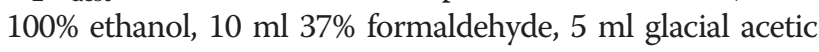
acid), the brain was dissected and silver intensified: $60 \mathrm{~min}$ at $50^{\circ} \mathrm{C}$ in dark in solution $\mathrm{A}\left(10 \mathrm{ml} \mathrm{H}_{2} \mathrm{O}_{\text {dest }}, 3 \mathrm{ml} 100 \%\right.$ ethanol, $0.5 \mathrm{~g}$ gum arabic, and $0.02 \mathrm{~g}$ hydroquinone; $\mathrm{pH}$ value adjusted to between 2.6 and 3.1 using citric acid), and $15-30 \mathrm{~min}$ at $50^{\circ} \mathrm{C}$ in the dark in solution $\mathrm{B}\left(10 \mathrm{ml} \mathrm{H}_{2} \mathrm{O}_{\text {dest }}\right.$, $3 \mathrm{ml} \mathrm{100 \%}$ ethanol, $0.5 \mathrm{~g}$ gum arabic, $0.02 \mathrm{~g}$ hydroquinone, $0.01 \mathrm{~g} \mathrm{AgNO}_{3} ; \mathrm{pH}$ value adjusted to between 2.6 and 3.1 using citric acid). Silver intensification was stopped in an acetic acid solution $(50 \mathrm{ml} 30 \%$ ethanol, $5 \mathrm{~g}$ glucose, $\mathrm{pH}$ value adjusted to between 2.6 and 3.1 using acetic acid). After dehydration in a graded acetone series, the brain was 
embedded in Glycidether 100, and sectioned with a rotary microtome and stainless steel blade in the sagittal, frontal, and transversal planes $(14-16 \mu \mathrm{m})$.

\section{Dil / DiO labelling}

(Euscorpius hadzii, after Wohlfrom and Melzer [43]): The cephalothorax was dissected and fixed overnight at $4^{\circ} \mathrm{C}$ in $4 \%$ formaldehyde in 0.1 M PBS. Afterwards specimens were rinsed overnight in $0.1 \mathrm{M} \mathrm{PBS}, 0.1 \% \mathrm{NaN}_{3}$. Finally, small DiI or DiO crystals (Molecular Probes) were inserted in median or median and lateral eyes with a fine tungsten needle. Diffusion was carried out in darkness on small glass slides enclosed in wet chambers for 17-22 days. To prevent the growth of microorganisms, $\mathrm{NaN}_{3}$ in PBS was used for moistening. From time to time the specimens were controlled under the microscope. Specimens were studied with a fluorescence microscope and CLSM.

\section{Osmium ethyl gallate procedure}

(Euscorpius italicus, modified after Wigglesworth [44], Leise and Mulloney [45], and Mizunami et al. [46]): Brains were dissected and fixed in $4 \%$ glutardialdehyde in $0.1 \mathrm{M}$ cacodylate buffer at $4{ }^{\circ} \mathrm{C}(\mathrm{n}=7)$. After postfixation in $2 \% \mathrm{OsO}_{4}$ in $0.1 \mathrm{M}$ cacodylate buffer $\left(3 \mathrm{~h}\right.$ at $\left.4^{\circ} \mathrm{C}\right)$ animals were stained for 17 hours at $4^{\circ} \mathrm{C}$ in a saturated ethyl gallate solution, dehydrated in a graded acetone series, embedded in Glycidether 100, and sectioned with a rotary microtome and stainless steel blade in the sagittal, frontal, and transversal planes $(5-8 \mu \mathrm{m})$.

\section{D-reconstruction}

Brain (prepared as for Cobalt fills) was cut into a complete sagittal series $(16 \mu \mathrm{m})$. Slices were mounted on glass slides, covered with cover slips, and photographed under a conventional light microscope. Images were contrast-enhanced in Adobe Photoshop, then aligned, segmented and rendered in Amira.

\section{Competing interests}

The authors declare that they have no competing interests.

\section{Authors' contributions}

$T L$ conceived the study, carried out the morphological analysis, and drafted the manuscript. RRM conceived and supervised the study and helped writing the paper. All authors read and approved the final manuscript.

\footnotetext{
Acknowledgements

We thank Eva Lodde and Stefan Friedrich for expert technical assistance; Carolin Schneider, Stefan Friedrich, and Roland Meyer for help with collecting the animals (E. italicus); Christian Kronmüller and b.t.b.e. Insektenzucht $\mathrm{GmbH}$ (Schnürpflingen, Germany) for providing E. hadzii specimens; Martin Heß for his help at the CLSM; and Martin Spies for polishing the English. This study was supported by a Graduiertenstipendium (BayEFG) from the Universität Bayern e.V. to T. Lehmann. We would like to express our gratitude to the anonymous reviewers, whose comments have helped a lot to improve the manuscript.
}

\section{Author details}

'SNSB - Bavarian State Collection of Zoology, Münchhausenstraße 21,

Munich 81247, Germany. ${ }^{2}$ Department Biology II,

Ludwig-Maximilians-Universität München, Großhaderner Straße 2,

Planegg-Martinsried 82152, Germany. ${ }^{3}$ GeoBio-Center at LMU,

Richard-Wagner-Str. 10, 80333, Munich, Germany.

Received: 11 December 2012 Accepted: 1 July 2013

Published: 11 July 2013

\section{References}

1. Ruppert EE, Fox RS, Barnes RD: Invertebrate zoology: a functional evolutionary approach. 7th edition. Belmont: Thomson-Brooks/Cole; 2004.

2. Bedini C: The fine structure of the eyes of Euscorpius carpathicus $L$. (Arachnida:Scorpiones). Arch Ital Biol 1967, 105:361-378.

3. Schliwa M, Fleissner G: The lateral eyes of the scorpion, Androctonus australis. Cell Tissue Res 1980, 206:95-114.

4. Locket A: Eyes and vision. In Scorpion Biology and Research. Edited by Brownell P, Polis G. Oxford: Oxford University Press; 448.

5. Spreitzer A, Melzer RR: The nymphal eyes of Parabuthus transvaalicus Purcell, 1899 (Buthidae): An accessory lateral eye in a scorpion. Zool Anzeiger 2003, 242:137-143.

6. Fleissner G: Neurobiology of a circadian clock in the visual system of scorpions. In Neurobiology of Arachnids. Edited by Barth FG. Berlin, Heidelberg, New York: Springer Verlag; 1986:385.

7. Holmgren N: Zur vergleichenden Anatomie des Gehirns von Polychaeten, Onychophoren, Arachniden, Crustaceen, Myriapoden und Insekten. Kungliga Svenska Vetenskapsakademien Handlingar 1916, 56:1-303.

8. Hanström B: Vergleichende Anatomie des Nervensystems der wirbellosen Tiere: unter Berücksichtigung seiner Funktion. Berlin: J. Springer; 1928.

9. Fleissner G: Intracellular Recordings of Light Responses from Spiking and Nonspiking Cells in the Median and Lateral Eyes of the Scorpion. Naturwissenschaften 1985, 72:46-48.

10. Paul DH: A neurophylogenist's view of decapod Crustacea. Bull Mar Sci 1989, 45:487-504.

11. Harzsch S: Neurophylogeny: Architecture of the nervous system and a fresh view on arthropod phyologeny. Integr Comp Biol 2006, 46:162-194.

12. Strausfeld NJ: Arthropod brains: evolution, functional elegance, and historical significance. Cambridge: Mass.: Harvard University Press; 2012.

13. Chamberlain SC, Barlow RB: Neuroanatomy of the visual afferents in the horseshoe crab (Limulus polyphemus). J Comp Neurol 1980, 192:387-400.

14. Calman BG, Lauerman MA, Andrews AW, Schmidt M, Battelle BA: Central projections of Limulus photoreceptor cells revealed by a photoreceptorspecific monoclonal antibody. J Comp Neurol 1991, 313:553-562.

15. Harzsch S, Vilpoux K, Blackburn DC, Platchetzki D, Brown NL, Melzer RR, Kempler KE, Battelle BA: Evolution of arthropod visual systems: development of the eyes and central visual pathways in the horseshoe crab Limulus polyphemus Linnaeus, 1758 (Chelicerata, Xiphosura). Dev Dyn 2006, 235:2641-2655.

16. Battelle BA: The eyes of Limulus polyphemus (Xiphosura, Chelicerata) and their afferent and efferent projections. Arthropod Struct Dev 2006, 35:261-274.

17. Oberdorfer MD: The Neural Organization of the First Optic Ganglion of the Principal Eyes of Jumping Spiders (Salticidae). J Comp Neurol 1977, 174:95-117.

18. Strausfeld NJ, Weltzien P, Barth FG: Two visual systems in one brain: neuropils serving the principal eyes of the spider Cupiennius salei. J Comp Neurol 1993, 328:63-75.

19. Strausfeld NJ, Barth FG: Two visual systems in one brain: neuropils serving the secondary eyes of the spider Cupiennius salei. J Comp Neurol 1993, 328:43-62.

20. Babu KS, Barth FG: Neuroanatomy of the central nervous system of the wandering spider, Cupiennius salei (Arachnida, Araneida). Zoomorphology 1984, 104:344-359.

21. Lehmann T, Hess M, Melzer RR: Wiring a Periscope - Ocelli, Retinula Axons, Visual Neuropils and the Ancestrality of Sea Spiders. PLoS One 2012, 7(1):30474. doi:10.1371/journal.pone-0030474

22. Mayer G: Structure and development of onychophoran eyes: what is the ancestral visual organ in arthropods? Arthropod Struct Dev 2006, 35:231-245.

23. Strausfeld NJ, Strausfeld CM, Stowe S, Rowell D, Loesel R: The organization and evolutionary implications of neuropils and their neurons in the brain of the onychophoran Euperipatoides rowelli. Arthropod Struct Dev 2006, 35:169-196. 
24. Weygoldt P, Paulus HF: Untersuchungen zur Morphologie, Taxonomie und Phylogenie der Chelicerata. II. Cladogramme und die Entfaltung der Chelicerata. Zeitschrift Zool Syst Evol 1979, 17:177-200.

25. Shultz JW: Evolutionary morphology and phylogeny of Arachnida. Cladistics 1990, 6:1-38.

26. Shultz JW: A phylogenetic analysis of the arachnid orders based on morphological characters. Zool I Linn Soc 2007, 150:221-265.

27. Wheeler WC, Hayashi CY: The phylogeny of the extant chelicerate orders. Cladistics 1998, 14:173-192.

28. Giribet G, Edgecombe GD, Wheeler WC, Babbitt C: Phylogeny and systematic position of Opiliones: A combined analysis of chelicerate relationships using morphological and molecular data. Cladistics 2002, 18:5-70.

29. Masta SE, Longhorn SJ, Boore JL: Arachnid relationships based on mitochondrial genomes: Asymmetric nucleotide and amino acid bias affects phylogenetic analyses. Mol Phylogenet Evol 2009, 50:117-128.

30. Regier JC, Shultz JW, Zwick A, Hussey A, Ball B, Wetzer R, Martin JW, Cunningham CW: Arthropod relationships revealed by phylogenomic analysis of nuclear protein-coding sequences. Nature 2010, 463:1079-1083.

31. Dunlop JA, Webster M: Fossil evidence, terrestrialization and arachnid phylogeny. J Arachnol 1999, 27:86-93.

32. Braddy SJ, Aldridge RJ, Gabbott SE, Theron JN: Lamellate book-gills in a late Ordovician eurypterid from the Soom Shale, South Africa: support for a eurypterid-scorpion clade. Lethaia 1999, 32:72-74.

33. Strausfeld NJ: The evolution of crustacean and insect optic lobes and the origins of chiasmata. Arthropod Struct Dev 2005, 34:235-256.

34. Harzsch S: The phylogenetic significance of crustacean optic neuropils and chiasmata: a re-examination. J Comp Neurol 2002, 453:10-21.

35. Heinrichs $\mathrm{S}$, Fleissner $\mathrm{G}$ : Neuronal components of the circadian clock in the scorpion, Androctonus australis: Central origin of the efferent neurosecretory elements projecting to the median eyes. Cell Tissue Res 1987, 250:277-285.

36. Homberg U: Evolution of the central complex in the arthropod brain with respect to the visual system. Arthropod Struct Dev 2008, 37:347-362.

37. Westheide W, Rieger R: Spezielle Zoologie: Teil 1: Einzeller und Wirbellose Tiere. Heidelberg, Berlin: Spektrum Akademischer Verlag; 2006.

38. Meusemann K, von Reumont BM, Simon S, Roeding F, Strauss S, Kuck P, Ebersberger I, Walzl M, Pass G, Breuers S, et al: A phylogenomic approach to resolve the arthropod tree of life. Mol Biol Evol 2010, 27:2451-2464.

39. Campbell LI, Rota-Stabelli O, Edgecombe GD, Marchioro T, Longhorn SJ, Telford MJ, Philippe H, Rebecchi L, Peterson KJ, Pisani D: MicroRNAs and phylogenomics resolve the relationships of Tardigrada and suggest that velvet worms are the sister group of Arthropoda. Proc Natl Acad Sci USA 2011, 108:15920-15924.

40. Strausfeld NJ, Strausfeld CM, Loesel R, Rowell D, Stowe S: Arthropod phylogeny: onychophoran brain organization suggests an archaic relationship with a chelicerate stem lineage. Proc R Soc B 2006, 273:1857-1866.

41. Schliwa M, Fleissner G: Arhabdomeric Cells of the Median Eye Retina of Scorpions. I. Fine Structural Analysis. J Comp Physiol 1979, 130:265-270.

42. Altman JS, Tyrer NM: Filling selected neurons with cobalt through cut nerves. In Neuroanatomical Techniques: Insect Nervous System. Edited by Strausfeld NJ, Miller TA. New York: Springer; 1980:496.

43. Wohlfrom H, Melzer RR: Development of the sensory system in larvae and pupae of Chaoborus crystallinus (DeGeer, 1776; Diptera, Chaoboridae): sensory cells, nerves and ganglia of the tail region. Dev Genes Evol 2001, 211:124-137.

44. Wigglesworth VB: The use of osmium in the fixation and staining of tissues. Proc Roy Soc London Ser B 1957, 147:185-199.

45. Leise EM, Mulloney B: The Osmium-Ethyl Gallate Procedure is Superior to Silver Impregnations for Mapping Neuronal Pathways. Brain Res 1986, 367:265-272.

46. Mizunami M, Iwasaki M, Nishikawa M, Okada R: Modular structures in the mushroom body of the cockroach. Neurosci Lett 1997, 229:153-156.

doi:10.1186/1742-9994-10-40

Cite this article as: Lehmann and Melzer: Looking like Limulus? Retinula axons and visual neuropils of the median and lateral eyes of scorpions. Frontiers in Zoology 2013 10:40.

\section{Submit your next manuscript to BioMed Central and take full advantage of:}

- Convenient online submission

- Thorough peer review

- No space constraints or color figure charges

- Immediate publication on acceptance

- Inclusion in PubMed, CAS, Scopus and Google Scholar

- Research which is freely available for redistribution

Submit your manuscript at www.biomedcentral.com/submit
( BioMed Central 